Erratum

\title{
Erratum to "Minimally Invasive Treatment of the Thoracic Spine Disease: Completely Percutaneous and Hybrid Approaches"
}

\author{
Francesco Ciro Tamburrelli, Laura Scaramuzzo, Maurizio Genitiempo, and Luca Proietti \\ Department of Spinal Surgery, Catholic University of Rome, $\lg$ A. Gemelli 8, 00135 Rome, Italy \\ Correspondence should be addressed to Francesco Ciro Tamburrelli; f.tamburrelli@tiscali.it \\ Received 14 March 2014; Accepted 20 March 2014; Published 6 April 2014 \\ Copyright (C) 2014 Francesco Ciro Tamburrelli et al. This is an open access article distributed under the Creative Commons \\ Attribution License, which permits unrestricted use, distribution, and reproduction in any medium, provided the original work is \\ properly cited.
}

The authors' names were incorrectly listed as Tamburrelli Francesco Ciro, Scaramuzzo Laura, Genitiempo Maurizio, and Proietti Luca are corrected as stated above. 


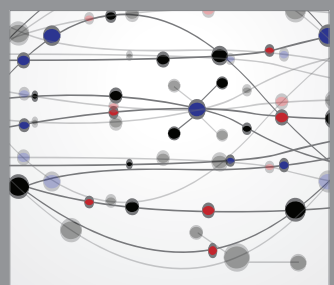

The Scientific World Journal
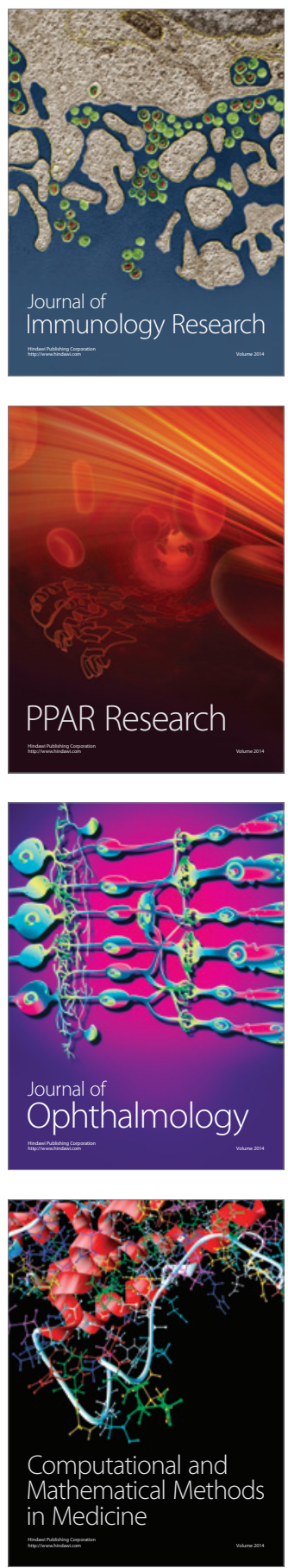

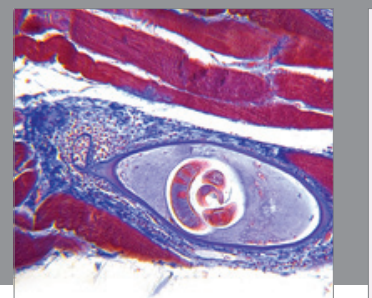

Gastroenterology

Research and Practice
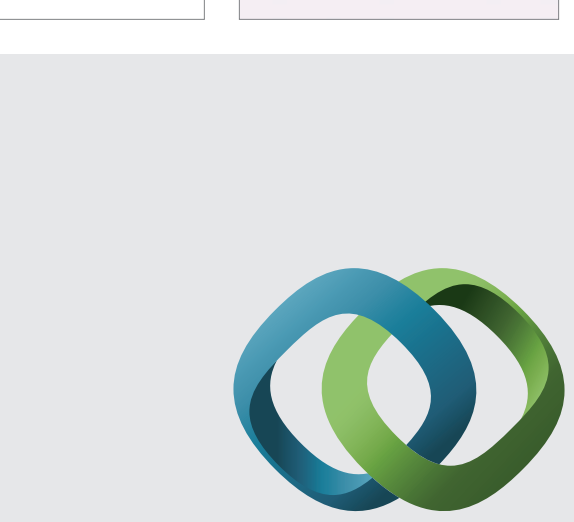

\section{Hindawi}

Submit your manuscripts at

http://www.hindawi.com
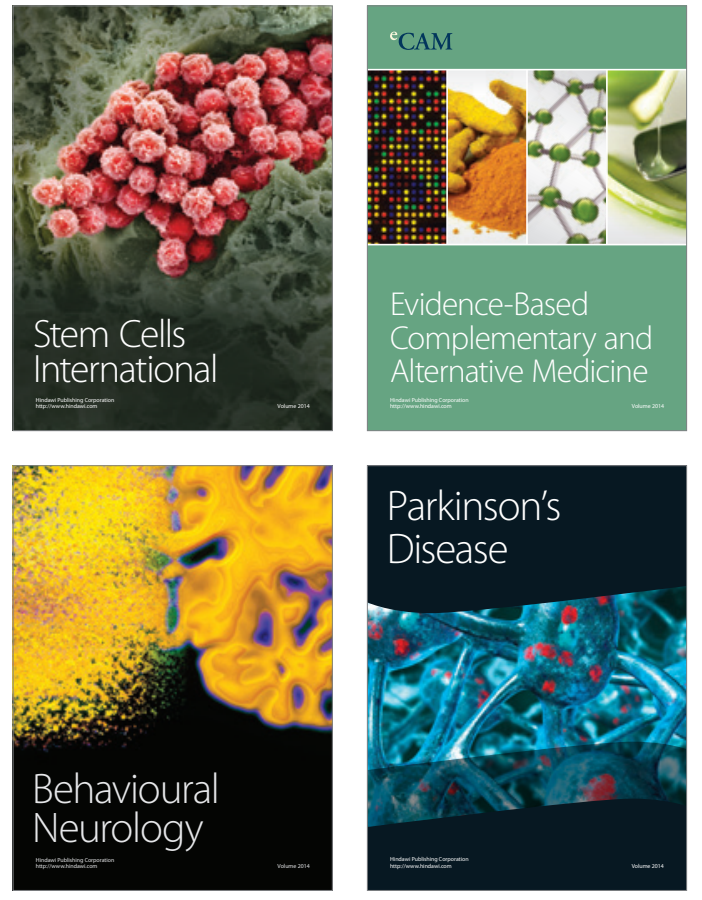
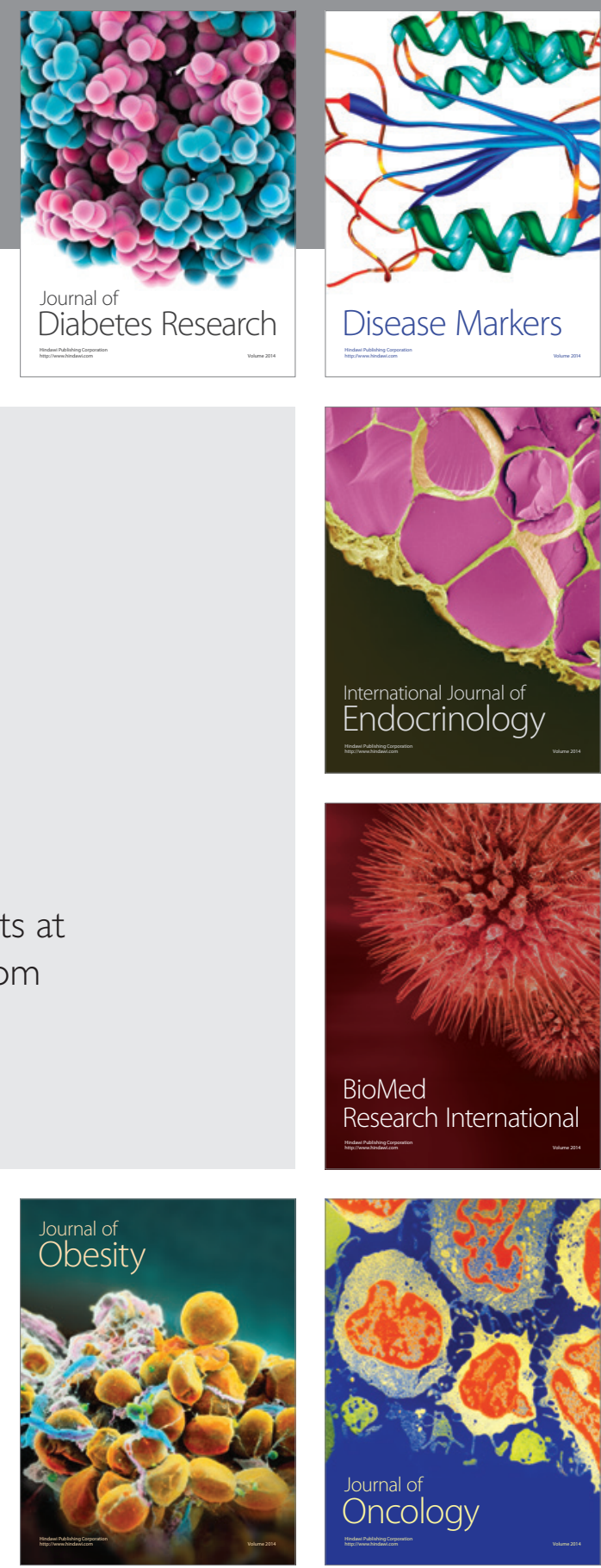

Disease Markers
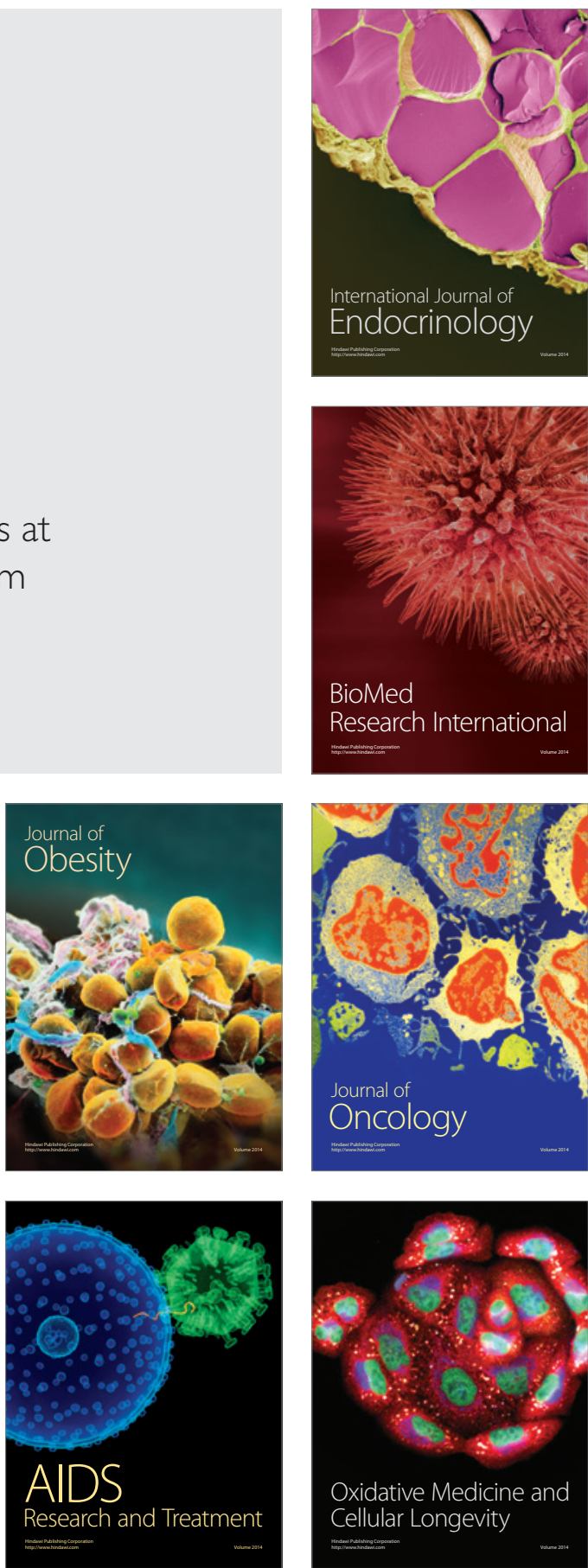